\title{
Jan Czochralski and His Method of Pulling Crystals
}

The most advanced factories, or "fabs," in which integrated circuits are made use circular slices of silicon $300 \mathrm{~mm}$ in diameter. They are sliced from huge single crystals that are drawn from a molten silicon bath; these massive crystal ingots are rotated as they are slowly raised in synchrony with their growth rate, and the process has been perfected to the point where the dislocation population is about a million times lower than in a normal crystal. This procedure was initially developed by Gordon Teal and his colleagues at Bell Laboratories and then at Texas Instruments, from 1948 to 1952 . However, the process was by no means entirely new.

The scientist who discovered the process on which this modern procedure was based was Jan Czochralski (18851953). According to one of his nephews, Czochralski (pronounced cho-HRALskee) based his experiment upon an accidental incident. One day, after melting some tin in a small dish with the intention of performing an experiment with it, Czochralski interrupted his work to write some notes. Absent-mindedly, he dipped his steel pen nib into the tin instead of the adjacent inkwell, then drew it out and found a thin filament of solid metal hanging from it; the slit in the nib had acted as a nucleating site for the solid. Instead of cursing, he perceived the significance of the accident and exploited it.

In the middle of the First World War (1916), in Berlin, Czochralski designed a simple apparatus for measuring the crystal growth rate from the melt for a number of metals and submitted it in that year to the Zeitschrift für physikalische Chemie, which-slowed by the desperate circumstances of the time-delayed publication of the short paper until 1918. The apparatus (see Figure 1) consisted of a simple mechanism for dipping a fine glass tube (with a hook at the upper end, attached to a silk thread) into a bath of molten metal-starting with tin and going on to lead and zinc-and raising the tube, with a thin rod of solid metal hanging from it, at a steady (adjustable) rate using a clockwork mechanism. When the rate of ascent matched the natural rate of crystal growth near the melting temperature, a long single crystal of uniform diameter resulted. If the rate of raising was too small or too great, the solid rod either became thickened and short or attenuated and broke off. The single-crystal nature of the rod under ideal conditions was verified by etching. In later years, Czochralski applied the same method to several other metals.

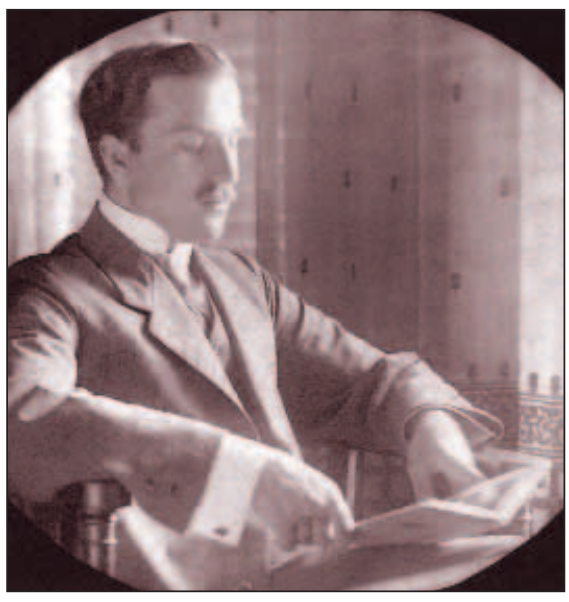

Jan Czochralski

Physical chemist and philosopher Michael Polanyi, in 1921-1922, also in Berlin, improved the method by floating on the melt a sheet of mica with a small hole in it, as a means of assuring a neat circular cross section for the crystal, and used this variant as a means of making monocrystals (e.g., of zinc) with the aim of examining plastic deformation (see Figure 2). But this did not alter the essential nature of Czochralski's discovery. Twenty-six years later, Teal (1908-2003) struggled with colleagues and managers at Bell Laboratories to force through his conviction that a Czochralski-type procedure for Ge and Si was the correct method for making high-quality transistors; until he finally had his way, the pioneers at Bell Labs were erroneously convinced that polycrystalline germanium or silicon was adequate. Teal did not cite Czochralski explicitly, but it is clear from citations in his patents that he was familiar with Czochralski's method. In Europe, at least, Czochralski was famous in his heyday. His method was described in some detail and attributed to him in a 1949 survey of methods for growing metal crystals by A.N. Holden, published by ASM.

Born in Poland, Czochralski worked in a drugstore near his hometown just before moving to Berlin in his late teens, where he again worked in a drugstore. At that time, he studied part-time at a technical university in Berlin-Charlottenburg and subsequently worked in the laboratories of several technical enterprises. He had an impressive career between 1917, when he was engaged to create a research laboratory for Metallgesellschaft in Frankfurt am
Main (which in due course became the leading German metallurgical firm), and 1939, when his research came to an end. He worked in Frankfurt until 1929, and among other achievements, he played a major role in creating the Zeitschrift für Metallkunde and later, the scientific society Deutsche Gesellschaft für Metallkunde. Throughout his years as a researcher and research director, Czochralski mixed

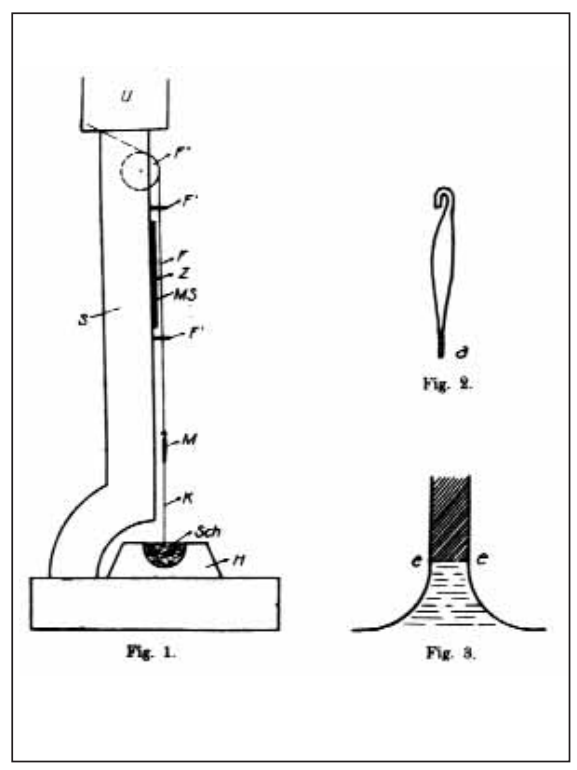

Figure 1. Schematic illustration of Czochralski's method, published in Zeitschrift für physikalische Chemie 92 (1918) p. 220

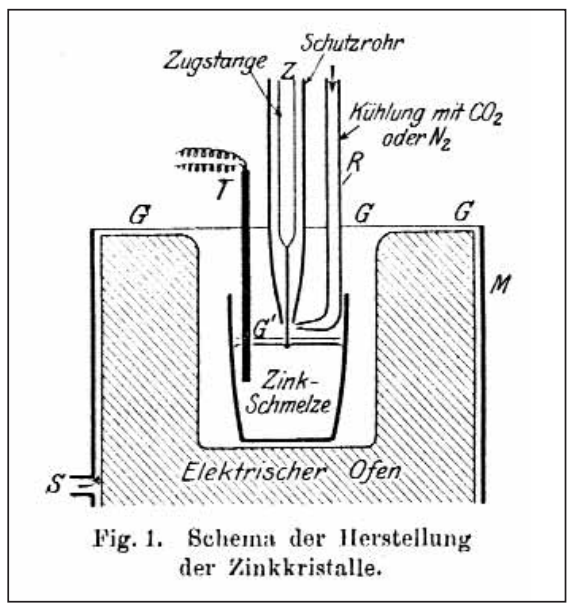

Figure 2. Schematic illustration of Czochralski's method as modified by Mark, Polanyi, and Schmid; published in Zeitschrift für Physik 12 (1923) p. 58. 
applied metallurgy with purely curiositydriven investigations. According to a history of the Frankfurt laboratory privately published in 1981, he ran a "severe and hard regime" and was feared as chief engineer. In 1929, he was invited by the president of Poland to return to his native land, which he duly did, and there he was put in charge of the chemistry department of the Warsaw University of Technology. In 1939, upon the invasion by Germany, all Polish universities were closed, and thereafter Czochralski worked full-time in manufacturing. The German metallurgical community may possibly have taken his departure to Poland badly; when he died in 1953, he received no obituary in the Zeitschrift für Metallkunde, which he had had a major part in founding in 1911.

In Poland, Czochralski invested the fortune he brought from Germany in industry and in scholarships for the arts, set up a consulting laboratory for metallurgy, and did much work for the Polish military. During World War II, he contrived to aid the clandestine National Army and help the persecuted individuals in Warsaw, while cautiously keeping on the right side of the Germans by undertaking some manufacturing tasks for them. After the war, Czochralski was accused as a collaborator and traitor and relieved of his university post. He retired with great bitterness to his hometown Kcynia and founded a drugs and cosmetics firm to keep himself occupied. After his death, he was forgotten for many years; indeed, it is possible that his erstwhile German colleagues did not know of his death and that was why he was not commemorated in the Zeitschrift für Metallkunde.
Recently, however, a monument in his memory has been erected in his hometown.

For Further REAding: P. Tomaszewski, "Professor Jan Czochralski and His Contribution to the Art and Science of Crystal Growth," AACG [American Association for Crystal Growth] 27 (2) (1998) p. 12; J. Czochralski, Zeitschrift für physikalische Chemie 92 (1918) p. 219; and A.N. Holden, "Preparation of Metal Single Crystals," Preprint, No. 35, American Society for Metals (1949) p. 29.

PAWE€ E. TOMASZEWSKI Polish Academy of Sciences E-mail PETomasz@int.pan.wroc.pl

ROBERT W. CAHN University of Cambridge E-mail rwc12@cam.ac.uk

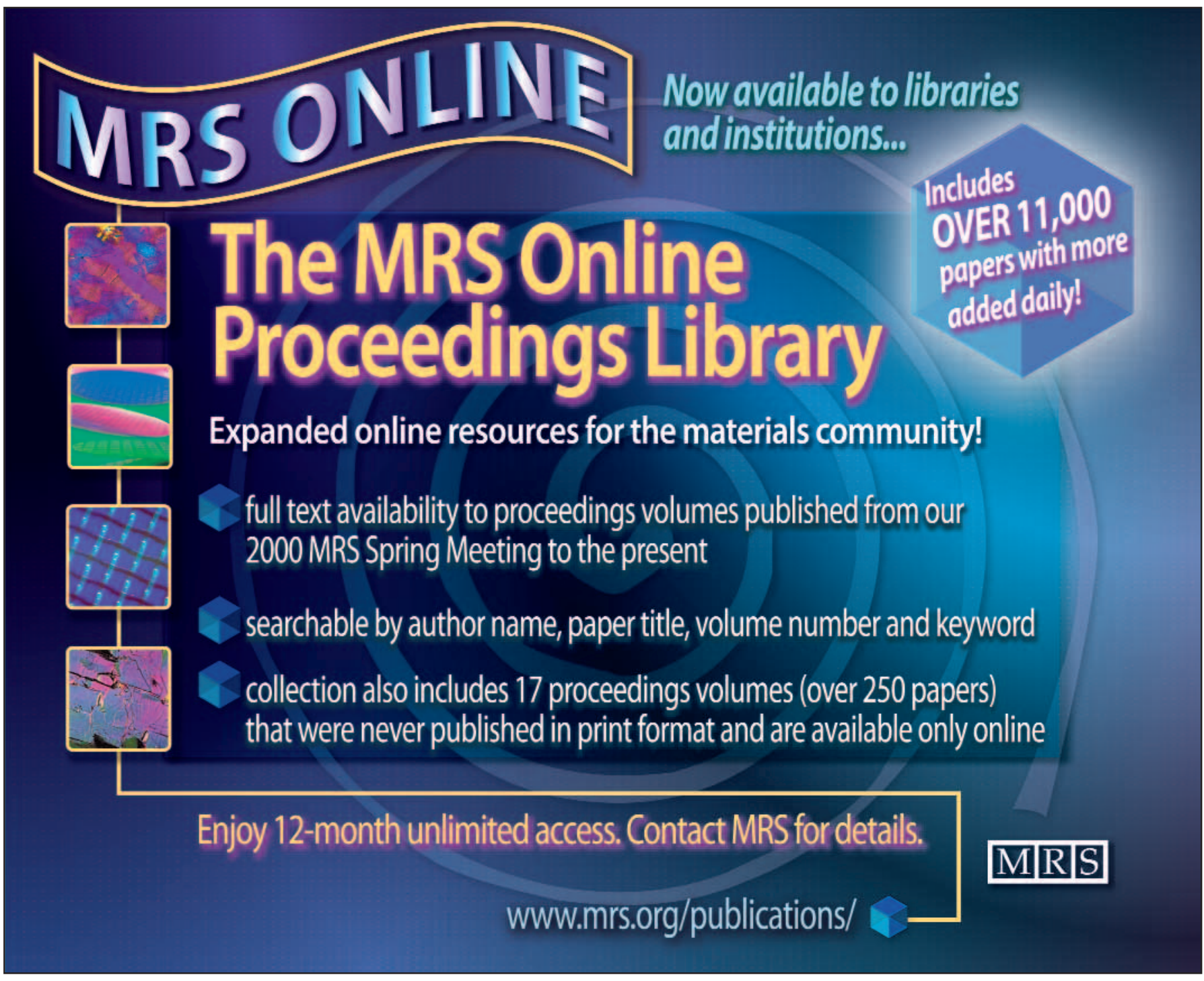

